\title{
In Situ SiRNA Assembly in Living Cells for Gene Therapy with MicroRNA Triggered Cascade Reactions Templated by Nucleic
}

\section{Acids}

Kewei Ren, ${ }^{\dagger, \|}$ Yue Zhang, ${ }^{\dagger, \|}$ Xiaobo Zhang, ${ }^{\dagger}$ Ying Liu,,${ }^{, \dagger}$ Min Yang ${ }^{\ddagger} \&$ Huangxian Ju*, ${ }^{*}{ }^{\dagger}$

'State Key Laboratory of Analytical Chemistry for Life Science, School of Chemistry and Chemical Engineering, Nanjing University, Nanjing 210023, P.R. China.

Department of Pharmaceutical \& Biological Chemistry, UCL School of Pharmacy, University College London, London WC1N 1AX, UK.

* Corresponding authors. Phone/fax: +86-25-89681918. E-mail: yingliu@ nju.edu.cn (Y. Liu) Phone/fax: +86-25-89683593. E-mail: hxju@nju.edu.cn (H. X. Ju) 
ABSTRACT: The in situ generation of siRNAs in living cells can greatly enhance the specificity and efficiency of gene therapy. Inspired by the natural molecular machines that organize different compartments sequentially in a limited space to facilitate cellular process, this work constructs a DNA nanomachine (DNM) by alternately hybridizing two pairs of DNA/RNA hybrids to a DNA scaffold generated by rolling circle amplification for highly efficient in situ siRNA assembly in living cells. After target cell-specific delivery of DNM, intracellular specific microRNA can work as a trigger to operate the DNM by initiating DNA cascade displacement reaction between DNA/RNA hybrids along the scaffold for continuous generation of siRNAs. Using miR-21 as a model, efficient siRNAs generation are achieved via DNA templated cascade reaction, which demonstrated impressive suppressions to VEGF mRNA and protein expressions in cells and in vivo tumour growth, and indicated promising application of the designed strategy in gene therapy.

KEYWORDS: DNA nanomachine, siRNA generation, DNA templated cascade reaction, microRNA, gene interference 
Synthetic small interfering RNAs (siRNAs), which can intracellularly silence disease-causing genes, have been used as a class of medicines to treat cancers and a wide range of diseases such as amyotrophic lateral sclerosis, Huntington's disease (HD), Alzheimer's disease (AD), and Parkinson's disease (PD) ${ }^{1-4}$ One of the biggest challenges in RNA interfering (RNAi) based therapeutics is delivering the synthetic siRNAs into cells due to their cell impermeability and susceptibility to degradations..$^{5-7}$ Although a variety of nanoparticles, polymers, and DNA structures have been used as carriers for siRNA delivery, ${ }^{8-12}$ the unavoidable leakage of in vitro synthesized siRNA and uncontrollable degradation as well as "off-target" toxicity diminish gene therapy efficiency. ${ }^{13,14}$ Therefore, in situ generation of siRNA in target cells is an appropriate approach to enhance the specificity and efficiency of gene therapy, and several DNA/RNA hybridization/displacement reactions have been applied in living cells to in situ generate siRNA for gene therapies. ${ }^{15,16}$ However, the assembly efficiencies of current intracellular siRNA generation approaches through the spontaneous collisions of two DNA/RNA hybrids in molecularly crowded intracellular environment are limited due to the lacks of controllability and the low reaction rates. ${ }^{15}$ Developing a controlled siRNA assembly system with high reaction efficiency in dynamically changing cytoplasm is of great significance to precise gene therapy. ${ }^{17,18}$

The naturally occurring intracellular synthesis is relied on natural molecular machines that can organize different compartments sequentially in a limited space to carry out machinery work in tandem with one another to facilitate reaction process. ${ }^{19-21}$ A large number of natural intracellular molecular machines are composed of nucleic acid scaffolds such as transposons, spliceosomes, and ribosomes, which offer high reaction efficiency and specificity due to Watson-Crick base pairing. ${ }^{22,23}$ Inspired by the natural nucleic acid templated synthesis, programmable DNA nanostructures have been applied in vitro to assist cascade enzymatic reactions by substrate channeling ${ }^{24,25}$ and cofactor, ${ }^{26}$ as well as to guide sequence-defined polymer and peptide synthesis. ${ }^{27-30}$ The nucleic acid templated 
small reaction area confines free diffusion of reactants and enhances their local concentrations, which can accelerate the reaction and greatly improve reaction efficiency. ${ }^{31,32}$ However, the application of DNA templated synthetic reactions has not been extended into living cells due to the involvement of exotic enzymes and catalyst.

Here we designed a strategy for in situ assembly of siRNA in living cells via microRNA (miRNA or miR) driving cascade reaction in a DNA nanomachine (DNM). The DNM was constructed by alternately hybridizing two pairs of DNA/RNA hybrids (DR and D'R') to a DNA scaffold. The proximity and precise arrangement of DR and D'R' along the scaffold guaranteed high reaction efficiency for intracellular siRNA generation. ${ }^{33,34}$ Using miR-21 as the specific model trigger to operate the DNA cascade strand displacement reaction in DNM, the continuous generation of siRNA was proceeded along the DNA scaffold, which was precisely controllable in time and space. The highly efficient gene silencing to suppress mRNA and protein expressions in cells and in vivo tumour growth demonstrated the practicability of this approach in gene therapy. Compared with the

conventional gene interference technology, ${ }^{35,36}$ the miR-21-triggered intracellular siRNA assembly with nucleic acids templated cascade reactions provides higher therapeutic specificity than that directly delivers siRNA into cells, and improves delivery stability by substituting the duplex siRNA with DNM. The high biocompatibility, impressive controllability and reaction efficiency of miR-21-triggered DNM could be further extended to in situ generation and biosensing of other nucleic acids and biomolecules.

\section{RESULTS AND DISCUSSION}

Principle of Intracellular SiRNA Assembly with MiRNA-Triggered DNM. As shown in Figure 1a, the DNA/RNA hybrids (DR and D'R') were alternatively arranged on a DNA scaffold, which was previously produced by rolling circle amplification (RCA), to form DNM. DR and D'R' 
were synthesized by hybridizing ssDNA (D or D') with specific RNA (R or R') respectively, which formed two complementary bulge loop conformations. ${ }^{37,38}$ Here the 5 ' end of R is labelled with Cy3 (Cy3-R) for in situ monitoring the cellular process, and its 3' end has a toehold complementary to 5' end of specific miRNA. ${ }^{39}$ The negatively charged DNM could form stable nanocomposite with cationic folic acid modified polyethylenimine (FPEI) to facilitate target cell-specific delivery and assist the endosomal escape of DNM into the cytoplasm. ${ }^{40}$ Afterward, intracellular specific miRNA could recognize the toehold of $\mathrm{R}$ and hybridize with the first 22 nucleotides of $\mathrm{R}$ starting from the 3'-end to open the bulge loop of DR. The released bulge loop of D worked as an activated toehold to react with the bulge loop of $\mathrm{D}^{\prime}$ subsequently, which triggered the strand displacement reaction between DR and D'R' to generate dsDNA (DD') on the DNA scaffold and release both the siRNA $\left(\mathrm{RR}^{\prime}\right)$ and the miRNA from the DNM. ${ }^{16,38}$ The released miRNA triggered the next strand displacement reaction between DR and $\mathrm{D}^{\prime} \mathrm{R}^{\prime}$ for continuously generating siRNA in living cells (Figure 1b).

Characterization of DNM and DNM/FPEI. The synthesis of DNM was demonstrated by polyacrylamide gel electrophoresis (PAGE) analysis (Figure 2a). The RCA product showed a band with much lower mobility (lane 3) than DNA primer and DNA cycle (lanes 1 and 2), while the hybridization mixture showed only one band with much lower mobility (lane 6) than DR and D'R' (lanes 4 and 5), suggesting the formation of DNA scaffold and the successful synthesis of DNM. Both the products of RCA and DNM barely moved in polyacrylamide gels due to their large molecular masses and sizes. ${ }^{41,42}$ Atomic force microscopic (AFM) image of DNM demonstrated monodispersed branch-like structure with an average length of $250 \pm 100 \mathrm{~nm}$ (Figure 2b). Considering the 48-base length of DNA cycle $(16 \mathrm{~nm})^{43}$ for forming the repeated sequences to hybridize DR and D'R', the DNM contained $16 \pm 6$ pairs of DR/D'R'. To further confirm the number, aminomethylcoumarin (AMCA)-labelled DNA primer, Cy3-R and Cy5-labelled R' were used to 
synthesize the tricolor DNM. From the fluorescence signals of AMCA, Cy3 and Cy5 in the DNM, the ratios of DNM : DR : D'R' were about $1: 16.9: 17.0$ (Figure S1), which was consistent with the AFM result.

To evaluate the performances and applications of DNM, self-quenched DR (SQ-DR) was prepared with Cy3-R and corresponding quencher BHQ2-labelled D to synthesize a self-quenched DNM (SQ-DNM). Upon addition of 10\% fetal bovine serum, the fluorescence recovery of free SQ-DR was much greater than the SQ-DNM (Figure S2a), suggesting that DNM provided good protection of DR against nuclease degradation. The melting temperature $\left(\mathrm{T}_{\mathrm{m}}\right)$ of $77.6{ }^{\circ} \mathrm{C}$ indicated good thermal stability of the DNM (Figure S2b and S2c).

The synthetic FPEI was verified with its ${ }^{1}$ HNMR spectrum and the UV-VIS and FTIR spectra of FPEI, PEI and FA (Figure S3). Zeta potential analysis also confirmed the formation of DNM/FPEI (Figure S4), and the FPEI wrapping effectively compressed the size of DNM to around $100 \mathrm{~nm}$ (Figure $2 \mathrm{c}$ and $2 \mathrm{~d}$ ), which is more appropriate for cellular internalization..$^{44,45}$

Feasibility of SiRNA Assembly with MiRNA-Triggered DNM. The feasibility of miR-21 as a trigger to specifically initiate cascade strand displacement reaction in DNM for in situ siRNA generation was firstly verified via PAGE analysis (Figure 3a). After incubating $2 \mu \mathrm{M}$ DNM with 10 nM miR-21, a band representing RR' (lane 1) appeared (lane 3), indicating the successful generation of siRNA. The assembly efficiency was calculated from the intensity of the generated siRNA band, which was about $58.5 \%$ with the DNM/miR-21 molar ratio of 200 , indicating the high siRNA generation efficiency. Incubating DNM with control miRNA (miR-145) did not yield any new band (lanes 4), demonstrating the high specificity of miRNA-triggered cascade strand displacement reaction. The strong fluorescence of $\mathrm{Cy} 3$ could be observed from SQ-DNM in the presence of miR-21 due to the formation of BHQ2-DD' on the DNM and release of Cy3-RR', while it was very weak in the mixtures of miR-145 with SQ-DNM, or the mixture of miR-21 with SQ-NR-DNM that 
was not responsive to miR-21 (Figure 3b), further confirming the reaction specificity of miR-21-triggered cascade strand displacement reaction between DR and D'R'. The specificity of DNM in response to miR-21 for siRNA generation was also demonstrated by comparing the responses of DNM to single-base mismatched miR-21, three-base mismatched miR-21 and miR-145 (Figure S5). The formation of RR' was also demonstrated by the FRET signal of tetramethylrhodamine (TAMRA)-labelled R' from bicolor DNM prepared with 5-carboxyfluorescein (FAM)-labelled R and TAMRA-labelled R' after incubated with miR-21 (Figure 3c). Moreover, this signal was positively depended on miR-21 concentration.

To demonstrate the effect of interval distance between DR and D'R' in DNM on the efficiency of siRNA generation, a serial of DNMs with different base numbers between DR and D'R' were prepared. In the presence of $10 \mathrm{nM}$ miR-21, the highest siRNA generation efficiency indicated by the fluorescence intensity was achieved at 8-bases distance (Figure S6). Hence, the DNM with 8-bases distance between DR and D'R' was used for subsequent experiments.

The kinetics for siRNA assembly via miRNA-triggered cascade strand displacement reaction of DR and D'R' in DNM was much quicker than that via random strand displacement reaction of DR and D'R' in homogeneous solution in the presence of miRNA (Figure S7). The former could reach the maximum generation in $16 \mathrm{~min}$, while the latter reached an equilibrium at $80 \mathrm{~min}$, demonstrating the substantial acceleration and highly efficient generation of siRNA.

To demonstrate the high efficiency of siRNA generation via miR-21-triggered DNM, the yield of siRNA from DNM was evaluated in vitro at different miR-21 concentrations by measuring Cy3 fluorescence recovery from SQ-DNM, which increased with the increasing miR-21 concentration (Figure 3d). At the reaction time of $60 \mathrm{~min}$ and the same miR-21 concentrations, the formed RR' showed much stronger fluorescence of $\mathrm{Cy} 3$ than that from the reaction of $\mathrm{DR}$ and $\mathrm{D}^{\prime} \mathrm{R}$ ' in homogeneous solution (Figure 3e). The Cy3 fluorescence of SQ-DNM in response to $50.0 \mathrm{pM}$ 
miR-21 was 12.4-times stronger than that from the mixture of SQ-DR and D'R', indicating the high efficiency of siRNA generation.

Intracellular SiRNA Assembly with MiRNA-Triggered DNM. The feasibility of intracellular siRNA generation from DNM was demonstrated with miR-21 and HeLa cells as model. After the cells were transfected with SQ-DNM/FPEI, Cy3 fluorescence in response to intracellular miR-21 was clearly observed (Figure 4), indicating the successful intracellular generation of siRNA. The nuclear localization images demonstrated complete fluorescence separation of 4',6-diamidino-2-phenylindole (DAPI) in nuclear from Cy3 in cytoplasm (Figure S9), indicating that the siRNA generation proceeded in cytoplasm. Here, the inhomogeneous intracellular fluorescence was attributed to the distribution of miR-21 in cytoplasm, which was infected by the inhomogeneous cellular environment. The fluorescence signal of $\mathrm{Cy} 3$ in $Z$-stack images exhibited a position-sensitive dependence, ${ }^{46}$ demonstrating intracellular localization of the generated siRNA (Figure S8). As control, the treatment of HeLa cells with SQ-NR-DNM/FPEI showed little intracellular fluorescence (Figure 4), indicating the specificity of miR-21 initiated intracellular siRNA generation. Furthermore, after the cells were treated with synthetic miR-21 antisense strands (anti-miR-21) to entirely suppress miR-21 expression (Figure S10) and then transfected with SQ-DNM/FPEI, they generated little Cy3 fluorescence (Figure 4). Flow cytometric assay showed the same results (Figure S11). The bicolor DNM labelled with FAM and TAMRA further confirmed the response specificity. After it was wrapped with FPEI and delivered into HeLa cells, successful intracellular FRET process was achieved between FAM and TRAMA upon the generation of siRNA, and only FAM fluorescence was observed when HeLa cells were incubated with bicolor NR-DNM/FPEI, or miR-21 expression-suppressed HeLa cells were incubated with bicolor DNM/FPEI (Figure S12). The intense FRET signal upon the operation of DNM via miR-21 activation in HeLa cells eliminated the false-positive signal from thermodynamic fluctuations and chemical interferences (such as nuclease 
and glutathione), ${ }^{47}$ thus confirmed the successful intracellular generation of siRNA.

The specific cell transfection of DNM/FPEI was achieved by folic acid (FA) receptor-mediated cell endocytosis, which was demonstrated by the much lower fluorescence recovery of Cy3 after the cells were incubated with SQ-DNM/PEI than that from SQ-DNM/FPEI transfected cells (DNM/PEI, DNM/FPEI, Figure S13). The internalization of SQ-DNM/FPEI could be highly suppressed for the cells previously treated with excessive FA (FA+DNM/FPEI, Figure S13), proving that FA played important roles in the targeted delivery of DNM/FPEI to HeLa cells. ${ }^{48}$ The transfection specificity was further verified by the negligible $\mathrm{Cy} 3$ fluorescence from the FA receptor-negative human epidermal HaCat cells after treated with SQ-DNM/FPEI (Figure S14).

To unequivocally evaluate the internalization pathway of the DNM/FPEI into the cells, a series of inhibitors including $\mathrm{NaN}_{3}$, wortmannin, genistein and sucrose were used to selectively block different cellular uptake processes (Figure S15). An obvious decrease in cellular uptake was observed when the cells were incubated with $\mathrm{NaN}_{3}$, indicating the energy-dependent internalization of DNM/FPEI. ${ }^{49}$ Moreover, the cells treated with genistein and sucrose caused $40-50 \%$ reduction in DNM/FPEI uptake, suggesting that DNM/FPEI experienced the caveole- and clathrin-dependent endocytosis pathways upon entering the cells. ${ }^{50}$

Gene Silencing and Cell Apoptosis Assays. Vascular endothelial growth factor (VEGF) was selected as a model target to evaluate the therapeutic effect of in situ siRNA generation. After HeLa cells were incubated with $100 \mathrm{nM}$ DNM/FPEI for $3 \mathrm{~h}$ and cultured in culture medium for $48 \mathrm{~h}$, the intracellular generation of siRNA effectively suppressed VEGF mRNA expression by $46.1 \%$ and VEGF protein expression by $47.3 \%$ due to the gene silencing. The control experiments using FPEI, NR-DNM/FPEI, FR-DNM/FPEI that could not perform strand displacement reaction to generate siRNA and NC-DNM/FPEI that could generate a negative control siRNA in the presence of miR-21 to transfect the HeLa cells showed little inhibition to VEGF mRNA expression and protein synthesis 
(Figure 5a and 5b). These results demonstrated the in situ specific formation of VEGF-related siRNA in HeLa cells.

MTT assay showed the inhibition effect of DNM/FPEI to HeLa cell proliferation. After HeLa cells were treated with DNM/FPEI for $3 \mathrm{~h}$ and cultured in DMEM for $48 \mathrm{~h}$, the cell proliferation obviously decreased in comparison to the untreated cells as control and the cells treated with FPEI, FR-DNM/FPEI, NC-DNM/FPEI and NR-DNM/FPEI (Figure S16). The latter ones did not show the inhibition effect. Moreover, the inhibition effect was dose-dependent, and the cell proliferation percentage decreased to $42.1 \%$ at $100 \mathrm{nM}$ DNM/FPEI. To evaluate the therapeutic effect of DNM/FPEI, the cell apoptosis was monitored with flow cytometry and Annexin V-FITC/PI apoptosis kit. The total apoptosis rate for DNM/FPEI treated cells was 50.1\%, while FPEI, FR-DNM/FPEI, NC-DNM/FPEI and NR-DNM/FPEI treated cells showed negligible apoptosis (Figure 5c), indicating that the in situ siRNA generation from DNM was a promising strategy for cancer gene therapy.

The high intracellular siRNA generation efficiency templated by nucleic acids to enhance the therapeutic effect was demonstrated by delivering SQ-DNM (DNM/Lipo) or the mixture of $100 \mathrm{nM}$ SQ-DR and D'R' ((DR + D'R')/Lipo) into HeLa cells. Here Lipofectamine 2000 was used to transfect DNM or the mixture for avoiding the effect of strand length of transfected nucleic acids on transfection efficiency of PEI. ${ }^{44}$ In comparison with $\left(\mathrm{DR}+\mathrm{D}^{\prime} \mathrm{R}\right) / \mathrm{Lipo}$, DNM/Lipo showed higher efficiencies for inhibiting VEGF mRNA and protein expressions (44.2\% and $42.6 \%$ respectively), restraining cell proliferation (40.4\%) and inducing apoptosis (40.8\%) (Figure S17), indicating the better therapeutic effect of DNM/FPEI than DNM/Lipo and the significant advantages of DNM assembly.

HepG2 cells were chosen to investigate the applicability of DNM/FPEI based siRNA therapy to other cancer cells. The bright fluorescence of $\mathrm{Cy} 3$ was observed in HepG2 cells treated with SQ-DNM/FPEI, indicating the successful intracellular generation of siRNA (Figure S18a), which 
was also verified by flow cytometric assay (Figure S18b). The VEGF mRNA and VEGF protein expressions in HepG2 cells treated with $100 \mathrm{nM}$ DNM/FPEI were inhibited by about $46.0 \%$ and 49.7\%, respectively (Figure S19a and S19b), and the cell proliferation decreased to $57.0 \%$ along with the raised apoptosis rate of $56.5 \%$ compared with the untreated cells and the cells treated with NC-DNM/FPEI (Figure S19c and S19d), indicating the potential therapeutic effect for various cancer types.

In Vivo Therapeutic Applicability. The antitumour efficacy of DNM via inhibition of VEGF expression from in vivo generated siRNA was investigated with mice bearing HeLa xenograft tumour. DNM/FPEI, NC-DNM/FPEI and NR-DNM/FPEI were intravenously injected into these mice every two days, respectively, and the inhibition efficacy towards tumour growth was monitored. DNM/FPEI presented effective inhibition efficacy towards tumour growth, while no therapeutic effect was observed for NC-DNM/FPEI and NR-DNM/FPEI treated mice compared with the control mice group (PBS injected) (Figure 6), indicating very high antitumour efficacy of DNM/FPEI. During the experiment period of 14 days, these mice did not show obvious variation in their body weights (Figure S19), indicating the satisfactory biocompatibility of DNM/FPEI. Thus in situ siRNA generation with DNM was a promising approach for highly efficient cancer therapy.

\section{CONCLUSIONS}

This work designs a miRNA triggered DNM to in situ assemble siRNA via cascade strand displacement reaction in cells. The highly efficient siRNA generation shows great suppression to miRNA-specific mRNA expression and protein synthesis in living cells. The DNM can be conveniently synthesized via alternately hybridizing two pairs of DNA/RNA hybrids to a DNA scaffold generated by rolling circle amplification, and shows satisfactory biocompatibility and good stability. Upon miRNA triggering, specific siRNA can be continuously assembled along the scaffold 
in a relatively short time due to the confined reaction area, which provides high reaction efficiency. Using VEGF as a model target, the continuously assembled siRNA via nucleic acids template can efficiently inhibit the proliferation of HeLa cells and the growth of HeLa xenograft tumour, and show exciting antitumour efficacy. This strategy can be easily extended for in situ generation of other genes by changing the corresponding hybrid pairs, thus possesses promising application in biosensing and precise gene therapy.

\section{METHODS}

Reagents. Phi29 DNA polymerase, T4 DNA ligase, exonuclease I, exonuclease III and dNTPs were purchased from New England Biolabs Ltd. Human VEGF ELISA kit and Annexin V-FITC apoptosis detection kit were purchased from BD Biosciences (USA). DNA purification kit was obtained from ComWin Biotech Co., Ltd (China). DAPI was purchased from KeyGEN Biotech (China). Lipofectamine 2000 was purchased from ThermoFisher scienticfic (USA). Linear polyethylenimine (PEI, 25,000), folic acid (FA), N-hydroxysuccinimide (NHS), and $\mathrm{N}$-(3-dimethylamino propyl-N'-ethylcar-bodiimide) hydrochloride $(\mathrm{EDC} \cdot \mathrm{HCl})$ were purchased from Sigma-Aldrich (USA). Phosphate buffer saline (PBS, pH 7.4) contained $136.7 \mathrm{mM} \mathrm{NaCl}, 2.7 \mathrm{mM}$

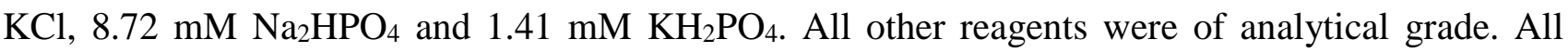
aqueous solutions were prepared using ultrapure water ( $\geq 18 \mathrm{M} \Omega$, Milli-Q, Millipore). RNAs were obtained from GenePharma Co. Ltd. (Shanghai, China). The RNA sequences were as follows: The RNA sequences were as follows:

VEGF RNA, sense,

Cy3-R: 5'-Cy3-GGAGUACCCUGAUGAGAUCAACAUCAGUCUGAUAAGCUA-3'

FAM-R: 5'-FAM-GGAGUACCCUGAUGAGAUCAACAUCAGUCUGAUAAGCUA-3'

Cy3-NR: 5'-Cy3-GGAGUACCCUGAUGAGAUCAACAUCAGUCUGA-3' 
FAM-NR: 5'-FAM-GGAGUACCCUGAUGAGA UCAACAUCAGUCUGA-3'

VEGF RNA, antisense,

R': 5'-UCAGACUGAUGUUGAUCUCAUCAGGGUACUCCGG-3'

TAMRA-R': 5'-UCAGACUGAUGUUGAUCUCAUCAGGGU ACUCCGG-TAMRA-3'

negative control RNA, sense,

5'-UUCUCCGAACGUGUCACUCAACAUCAGUCUGAUAAGCUA-3'

negative control RNA, antisense,

5'-UCAGACUGAUGUUGAGUGACACGUUCGGAGAAGG-3'

miR-21: 5'-UAGCUUAUCAGACUGAUGUUGA-3'

single-base mismatched miR-21: 5'-UAGAUUUAUCAGACUGAUGUUGA-3'

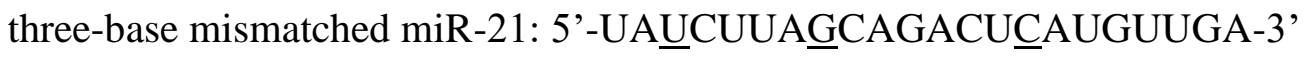

miR-145: 5'-GUCCAGUUUUCCCAGGAAUCCCU-3'

The mismatched bases were shown in underlined. All of the DNA were synthesized and purified by Sangon Biotech Co., Ltd (Shanghai, China). Their sequences were listed in Table S1.

Apparatus. Absorption spectra were recorded on an UV-3600 UV-Vis-NIR spectrophotometer (Shimadzu Company, Japan). The gel electrophoresis was performed on a DYCP-31BN Electrophoresis Analyser (Liuyi Instrument Company, China) and imaged on Bio-rad ChemDoc XRS (Bio-Rad, USA). Fluorescence spectra were measured on an F-7000 spectrometer (HITACHI, Japan). Confocal fluorescence imaging of cells was performed on a TCS SP5 confocal laser scanning microscope (Leica, Ger-many). Flow cytometric analysis was performed on a Coulter FC-500 flow cytometer (Beckman-Coulter). Real-time reverse transcription polymerase chain reaction (RT-PCR) was performed on a StepOneTM RT-PCR detection system (Applied Biosystems, USA). MTT and ELISA assays were carried out on Hitachi/Roche System Cobas 6000 (680, Bio-Rad, USA). AFM imaging was performed under ambient conditions with an Agilent 5500 AFM/SPM system (USA). 
Dynamic light scattering measurements were performed on a 90 Plus/BI-MAS equipment (Brook haven, USA). Infrared (IR) spectra were acquired on a Nicolet NEXUS870 Fourier transform infrared (FT-IR) spectrometer (Madison, WI). Zeta potential analysis was performed on Zetasizer (Nano-Z, Malvern, UK). 1HNMR spectra were recorded with a Bruker $500 \mathrm{MHz}$ spectrometer.

Preparation of DNA Cycle. $4.2 \mu \mathrm{L}$ of $100 \mu \mathrm{M}$ phosphorylated linear DNA and $4.2 \mu \mathrm{L}$ of 100 $\mu \mathrm{M}$ ligation DNA were mixed to anneal at $95{ }^{\circ} \mathrm{C}$ for $4 \mathrm{~min}$. After the mixture was cooled to room temperature over $2 \mathrm{~h}, 1 \mu \mathrm{L}$ of T4 DNA ligase (400 U/ $\mu \mathrm{L}), 2 \mu \mathrm{L}$ of $10 \times \mathrm{T} 4 \mathrm{DNA}$ buffer and $8.6 \mu \mathrm{L}$ ultrapure water were added, and the solution was incubated at $25^{\circ} \mathrm{C}$ for $16 \mathrm{~h}$. After T4 DNA ligase was inactivated by heating at $65{ }^{\circ} \mathrm{C}$ for $10 \mathrm{~min}, 4 \mu \mathrm{L}$ of exonuclease $\mathrm{I}(20 \mathrm{U} / \mu \mathrm{L})$ and $4 \mu \mathrm{L}$ of exonuclease III $(100 \mathrm{U} / \mu \mathrm{L})$ were added, respectively, and the mixture was then incubated at $37{ }^{\circ} \mathrm{C}$ for $8 \mathrm{~h}$ to degrade ligation DNA. Afterward, the mixture was heated at $80{ }^{\circ} \mathrm{C}$ for 15 min to denature the exonuclease I and exonuclease III. The generated DNA cycle was stored at $4{ }^{\circ} \mathrm{C}$ before use.

Preparation of DNA Scaffold. The DNA scaffold was synthesized by rolling circle amplification (RCA). ${ }^{51} 10 \mu \mathrm{L}$ of $3 \mu \mathrm{M}$ DNA cycle- 8 and $0.5 \mu \mathrm{L}$ of $100 \mu \mathrm{M}$ DNA primer were mixed and annealed at $95{ }^{\circ} \mathrm{C}$ for $4 \mathrm{~min}$. The mixture was slowly cooled to room temperature over $2 \mathrm{~h}$ and incubated with phi29 DNA polymerase $(0.2 \mathrm{U} / \mu \mathrm{L})$, BSA $(0.4 \mu \mathrm{g} / \mu \mathrm{L})$ and $\mathrm{dNTPs}(0.1 \mathrm{mM})$ at $37{ }^{\circ} \mathrm{C}$ for $5 \mathrm{~h}$ in $150 \mu \mathrm{L}$ of $1 \times \mathrm{Phi} 29$ reaction buffer. After RCA reaction, the mixture was incubated at $65^{\circ} \mathrm{C}$ for 10 min to denature the phi29 DNA polymerase, then purified by DNA purification kit to obtain the DNA scaffold.

As controls, a serial of DNMs with different numbers of bases between DR and D'R' were prepared with DNA cycle-4, DNA cycle-8, DNA cycle-12 and DNA cycle-16 as components, respectively.

Preparation of DNM. DR and D'R' were synthesized by mixing the stoichiometric amounts of D and Cy3-R ( $D^{\prime}$ and $\left.R^{\prime}\right)$ respectively at a final concentration of $10 \mu \mathrm{M}$ in PBS buffer. The resulting 
solutions were heated to $95{ }^{\circ} \mathrm{C}$ for $5 \mathrm{~min}$ and slowly $\left(1{ }^{\circ} \mathrm{C} / \mathrm{min}\right)$ cooled down to room temperature. 25 $\mu \mathrm{L}$ of $10 \mu \mathrm{M}$ DR, $25 \mu \mathrm{L}$ of $10 \mu \mathrm{M} \mathrm{D}^{\prime} \mathrm{R}^{\prime}$ and $300 \mu \mathrm{L}$ of DNA scaffold were mixed together for $2 \mathrm{~h}$ at $37{ }^{\circ} \mathrm{C}$ to hybridize DR and D'R' to DNA scaffold for the synthesis of DNM. The synthesized DNM was purified by ultrafiltration (100,000 MW cut-off membrane, Millipore) for three times.

To measure the amounts of DR and D'R' in purified DNM, aminomethylcoumarin (AMCA)-labelled DNA primer (AMCA-DNA primer), Cy3-R, and Cy5-labelled R' (Cy5-R') were used as components to synthesize a tricolor DNM. From the fluorescence intensities of three dyes in DNM and the standard calibration curves for AMCA-DNA primer, Cy3-R and Cy5-R', their amounts could be obtained.

As controls, NR-DNM that was not responsive to miR-21 was synthesized by using Cy3-NR, R', D and D' as components to hybridize with DNA scaffold, FR-DNM that could not generate siRNA was synthesized by hybridizing D and D' with DNA scaffold, and NC-DNM that could generate control siRNA was synthesized by using negative control RNA, ND and ND' as components to hybridize with DNA scaffold under the same conditions as DNM synthesis.

Polyacrylamide Gel Electrophoresis (PAGE) Analysis. 8\% native polyacrylamide gel was prepared using $1 \times \mathrm{TBE}$ buffer. The loading samples were prepared by mixing $7 \mu \mathrm{L}$ DNA samples, 1.5 $\mu \mathrm{L} 6 \times$ loading buffer and $1.5 \mu \mathrm{L}$ UltraPowerTM dye, and placed for $3 \mathrm{~min}$ before injected into polyacrylamide gel. The gel electrophoresis was run at $90 \mathrm{~V}$ for $60 \mathrm{~min}$ in $1 \times \mathrm{TBE}$ buffer, and scanned with a Molecular Imager Gel Doc XR.

The intensity of the bands in the gel images was measured using Adobe Photoshop software. The sum intensity of each band represents the total amount of the DNA sample, which was used to calculate the siRNA generation efficiency of miRNA-triggered DNM.

AFM Imaging. $6 \mu \mathrm{L}$ sample was deposited on freshly cleaved mica surface and incubated for 2 min. After the solvent water was absorbed with filter paper, $20 \mu \mathrm{L}$ ultrapure water was twice added 
to wash the mica. The mica was then dried with a nitrogen flow and scanned in tapping mode.

Serum Stability Assay of DNM. To verify the serum stability of DNM, Cy3 was tagged to R and black hole quencher (BHQ2) was tagged to D for the preparation of self-quenched DNA/RNA hybrids (SQ-DR) and the assembly of self-quenched DNM (SQ-DNM). The SQ-DNM and SQ-DR were separately diluted to $100 \mathrm{nM}$ with PBS containing $10 \%$ fetal bovine serum (FBS), and then incubated at $37{ }^{\circ} \mathrm{C}$ for $12 \mathrm{~h}$. During this process, the $\mathrm{Cy} 3$ fluorescence was measured with $510 \mathrm{~nm}$ excitation and $560 \mathrm{~nm}$ emission. The fluorescence from Cy3 was quenched at the beginning due to the close distance between Cy3 and BHQ2.

Thermal Stability Assay of DNM. The sample for thermal stability assay was prepared by mixing $19 \mu \mathrm{L}$ of $1 \mu \mathrm{M}$ DNM solution with $1 \mu \mathrm{L}$ of $20 \times \mathrm{SYBR}$ Green I in $0.2 \mathrm{~mL}$ PCR tubes (white). The fluorescence data at temperatures increasing from $30{ }^{\circ} \mathrm{C}$ to $90{ }^{\circ} \mathrm{C}$ at $0.2{ }^{\circ} \mathrm{C} / \mathrm{s}$ and holding for $15 \mathrm{~s}$ in every measurement point were measured to obtain the melting curves. ${ }^{48}$

In Vitro SiRNA Generation. To assess the in vitro generation of miR-21 controlled siRNA, 6 $\mu \mathrm{L}$ miR-21 with various concentrations were added in $54 \mu \mathrm{L}$ of $100 \mathrm{nM}$ SQ-DNM solution to incubate at $37{ }^{\circ} \mathrm{C}$ for $60 \mathrm{~min}$, respectively. The resulting mixtures were immediately subjected to fluorescence measurements. Fluorescence spectra were recorded with excitation at $510 \mathrm{~nm}$. The slit width was set as $5 \mathrm{~nm}$ for the excitation and $5 \mathrm{~nm}$ for the emission. The in vitro siRNA generation was also performed by mixing $54 \mu \mathrm{L}$ of $100 \mathrm{nM}$ SQ-DR and $100 \mathrm{nM} \mathrm{D}^{\prime} \mathrm{R}^{\prime}$ with $6 \mu \mathrm{L}$ miR-21 at various concentrations to incubate under the same condition for comparing the generation efficiency.

For FRET measurements, tetramethylrhodamine (TAMRA)-labelled R and 5-carboxyfluorescein (FAM)-labelled R' were used as components to assemble bicolor DNM. The fluorescence spectra were recorded with excitation at $488 \mathrm{~nm}$ and the excitation and emission slit widths of $5 \mathrm{~nm}$.

Preparation of Folic Acid Modified Polyethyleneimine (FPEI). After EDC (10 mg) and NHS (20 mg) were mixed with $20 \mathrm{~mL}$ of saturated folic acid $(0.0016 \mathrm{mg} / \mathrm{mL})$ to react at room 
temperature for $40 \mathrm{~min}$, polyethyleneimine (PEI) solution $(5 \mathrm{~mL}, 1 \mathrm{mg} / \mathrm{mL})$ was injected into the mixture to incubate at room temperature for $48 \mathrm{~h}$ with stirring. The reaction product was purified through dialysis with a membrane (MWCO: 7,000) for 6 days, and then freeze-dried under vacuum to obtain FPEI.

Assembly of DNM/FPEI. Purified DNM or SQ-DNM was mixed with FPEI at an N/P ratio of 10 and incubated at room temperature for $20 \mathrm{~min}$. The resulting nanocomposite was further diluted with PBS (pH 7.4) to $100 \mathrm{nM}$ for characterization and cell experiments.

As controls, NC-DNM/FPEI, NR-DNM/FPEI, and FR-DNM/FPEI nanocomposites were assembled by using NC-DNM, NR-DNM, and FR-DNM instead of DNM, respectively.

Cell Culture. Human cervix carcinoma (HeLa) cells (KeyGEN Biotech, Nanjing, China) were cultured in Dulbecco's modified Eagle's medium (DMEM) supplemented with 10\% FBS, $100 \mu \mathrm{g} / \mathrm{mL}$ streptomycin and $100 \mathrm{U} / \mathrm{mL}$ penicillin-streptomycin at $37{ }^{\circ} \mathrm{C}$ in a humidified incubator containing 5\% $\mathrm{CO}_{2}$ and $95 \%$ air. STR profiling and mycoplasma testing were conducted for each cell line before use. Cell numbers were determined with a Petroff-Hausser cell counter (USA).

Confocal Fluorescence Imaging and Flow Cytometric Assay. $1 \times 10^{4} \mathrm{HeLa}$ cells were seeded in a confocal dish and incubated in culture medium for $24 \mathrm{~h}$ at $37{ }^{\circ} \mathrm{C}$. The medium was then replaced with $200 \mu \mathrm{L}$ fresh culture medium containing $100 \mathrm{nM}$ SQ-DNM/FPEI and incubated at 37 ${ }^{\circ} \mathrm{C}$ for $3 \mathrm{~h}$. After washing twice with PBS, the fluorescence of cells was visualized from 550 to 610 $\mathrm{nm}$ on the confocal laser scanning microscope with the excitation wavelength of $514 \mathrm{~nm}$ for Cy3. All images were digitized and analyzed with Leica Application Suite Advanced Fluorescence (LAS-AF) software package. The flow cytometric assay was performed in PBS with FL2 channel.

For nuclear localization imaging, HeLa cells were incubated with $100 \mathrm{nM}$ SQ-DNM/FPEI for $3 \mathrm{~h}$ followed by staining with $5 \mu \mathrm{g} / \mathrm{mL}$ DAPI for $10 \mathrm{~min}$. DAPI was excited at $405 \mathrm{~nm}$ and the fluorescence signal was collected from 450 to $500 \mathrm{~nm}$. 
Endocytosis Pathway of DNM/FPEI. The endocytosis pathway was examined as follows: after HeLa cells were seeded in confocal dishes via 24-h incubation, $450 \mathrm{mM}$ sucrose, $200 \mu \mathrm{g} / \mathrm{mL}$ genistein, $50 \mathrm{nM}$ wortmannin and $10 \mathrm{mM} \mathrm{NaN}_{3}$ as uptake inhibitors were added into different cell-adhered dishes to inhibit clathrin, caveolae, macropinocytosis and energy dependent endocytosis, respectively. ${ }^{48,49}$ After incubation for $30 \mathrm{~min}$ at $37{ }^{\circ} \mathrm{C}$, these cells were loaded with SQ-DNM/FPEI nanocomposite, during which the inhibitors were maintained, to perform the flow cytometric analysis for measuring the uptake amount of SQ-DNM/FPEI.

MTT Assay. HeLa cells were seeded into two $96-$ well plates $\left(5 \times 10^{5}\right.$ per well) and incubated in $200 \mu \mathrm{L}$ culture medium for $24 \mathrm{~h}$ at $37^{\circ} \mathrm{C}$. The cells were then washed with PBS and incubated with serial concentrations of DNM/FPEI for $3 \mathrm{~h}$. As controls, FPEI, NR-DNM/FPEI, FR-DNM/FPEI and NC-DNM/FPEI were incubated with HeLa cells under the same conditions. After these cells were washed twice with PBS, $50 \mu \mathrm{L}$ of $5 \mathrm{mg} / \mathrm{mL}$ MTT solution was added to incubate for $4 \mathrm{~h}$. Afterward, the medium was removed, and $150 \mu \mathrm{L}$ of DMSO was added to dissolve the formazan crystal precipitates. After shaking the cell plate for $15 \mathrm{~min}$, the optical density (OD) at a wavelength of 490 $\mathrm{nm}$ was measured with a Bio-Rad microplate reader. The relative cell viability (\%) was calculated by $\left(A_{\text {test }} / A_{\text {control }}\right) \times 100 \%$.

Gene Silencing Assay. HeLa cells were seeded into 24 -well plate at $5 \times 10^{5}$ per well and incubated for $24 \mathrm{~h}$ at $37^{\circ} \mathrm{C}$. After the cells were washed with PBS, $100 \mathrm{nM}$ of DNM/FPEI was added to incubate for $3 \mathrm{~h}$ at $37^{\circ} \mathrm{C}$. Meanwhile, FPEI, NC-DNM/FPEI, NR-DNM/FPEI, and FR-DNM/FPEI were incubated with HeLa cells under the same condition as controls. After the medium was replaced by a fresh culture medium containing 10\% FBS and further cultured for $48 \mathrm{~h}$, the supernatant of culture medium was collected and analyzed by ELISA to quantify VEGF secreted from the cells. Total RNAs from the transfected HeLa cells were extracted using Trizol reagent (Invitrogen, USA), 
and cDNA of VEGF was generated using PrimeScriptRT reagent kit (Takara). The cDNA was detected with real-time PCR (RT-PCR) to calculate the level of cellular VEGF mRNA.

Cell Apoptosis Experiments. After $5.0 \times 10^{5} \mathrm{HeLa}$ cells were seeded in a 24 -well plate for 24 $\mathrm{h}$ at $37^{\circ} \mathrm{C}$, they were incubated with $200 \mu \mathrm{L}$ culture medium containing $100 \mathrm{nM}$ DNM/FPEI or FPEI, NC-DNM/FPEI, NR-DNM/FPEI, and FR-DNM/FPEI as controls for $3 \mathrm{~h}$ at $37^{\circ} \mathrm{C}$. The cells were further incubated for $48 \mathrm{~h}$ after the supernatant medium were replaced with fresh culture medium containing $10 \%$ FBS. The cells were then collected and stained with the mixture of $5.0 \mu \mathrm{L}$ Annexin V-FITC and 5.0 $\mu \mathrm{L}$ propidium iodide (PI) for $15 \mathrm{~min}$, and analyzed with flow cytometry over FL1 (Annexin V-FITC) and FL3 (PI) channels. Similar procedures were also performed for HepG2 cells to verify the therapeutic efficiency of the DNM/FPEI in other cancers.

To compare the therapeutic efficiencies for DNM and the mixture of DR and D'R', MTT assay, gene silencing assay and cell apoptosis experiments were conducted according to the above procedures except that HeLa cells were treated with the mixture of Lipofectamine $2000(0.5 \mu \mathrm{L})$ and DNM (100 nM, $200 \mu \mathrm{L})$ or the mixture of Lipofectamine $2000(0.5 \mu \mathrm{L})$ and DR/D'R' (200 nM, 100 $\mu \mathrm{L})$ for $3 \mathrm{~h}$ at $37^{\circ} \mathrm{C}$.

In Vivo Antitumour Efficacy. All animals were treated in according with institutional animal use and care regulations approved by the Jiangsu Simcere Pharmaceutical Research Institute, which allowed the maximal diameter (length) of every tumour should not exceed $20 \mathrm{~mm}$ or the volume of every tumour should be less than $2.0 \mathrm{~cm}^{3}$. Specific pathogen-free female BALB/c nude mice $(5-6$ weeks of age) were purchased from Shanghai Laboratory Animal Center, Chinese Academy of Sciences, and bred in an axenic environment. To set up a HeLa tumour model, $1.0 \times 10^{6}$ HeLa cells were subcutaneous injected into the selected position of the nude mice. When the tumour volumes reached to $75 \mathrm{~mm}^{3}$, the mice were randomly divided into four groups and intravenously injected with $50 \mu \mathrm{L}$ PBS, DNM/FPEI, NC-DNM/FPEI, and NR-DNM/FPEI at a dose of 500 pmol per mouse. The 
injections were performed every other day for five times and meanwhile the tumour sizes were measured every 2 days by a digital caliper for 14 days. The tumour volumes were calculated as $\mathrm{V}=$ $\left(\mathrm{L} \times \mathrm{W}^{2}\right) / 2$, where $\mathrm{L}$ and $\mathrm{W}$ are the length and width of the tumour, respectively.

\section{ASSOCIATED CONTENT}

The authors declare no competing financial interest.

\section{Supporting Information}

The Supporting Information is available free of charge on the ACS Publications website at DOI: http://pubs.acs.org.

Evaluation of DR/D'R' numbers assembled in DNM; characterization of DNM stability; characterization of FPEI synthesis and DNM/FPEI assembly; specificity evaluation miRNA-triggered siRNA assembly; effect of the distance between DR and D'R' in SQ-DNM on siRNA generation efficiency; kinetic analysis of miRNA-triggered siRNA assembly; z-stack images of HeLa cells; nuclear localization images; RT-PCR analysis of miR-21 in HeLa cells; characterization of siRNA assembly in HeLa cells; characterization of DNM/FPEI delivery specificity and its endocytosis pathways; HeLa cell proliferation assay; comparison of therapeutic efficiencies in presence and absence of DNA scaffold; characterization of siRNA assembly and therapeutic effect of DNM/FPEI in HepG2 cells; body weight variation of mice; and sequences of oligonucleotides (PDF)

\section{AUTHOR INFORMATION}

\section{Corresponding Authors}

*yingliu@nju.edu.cn;

*hxju@nju.edu.cn

\section{ORCID}


Huangxian Ju: 0000-0002-6741-5302

\section{Author Contributions}

"These authors contributed equally.

\section{ACKNOWLEDGMENTS}

We gratefully acknowledge National Natural Science Foundation of China (21605083, 21635005, 21361162002), Natural Science Foundation of Jiangsu Province (BK20160644), and the National Research Foundation for Thousand Youth Talents Plan of China. 


\section{References}

(1) Yu, D.; Pendergraff, H.; Liu, J.; Kordasiewicz, H. B.; Cleveland, D. W.; Swayze, E. E.; Lima, W. F.; Crooke, S. T.; Prakash, T. P.; Corey, D. R. Single-Stranded RNAs Use RNAi to Potently and Allele-Selectively Inhibit Mutant Huntingtin Expression. Cell 2012, 150, 895-908.

(2) Shi, J. J.; Kantoff, P. W.; Wooster, R.; Farokhzad, O. C. Cancer Nanomedicine: Progress, Challenges and Opportunities. Nat. Rev. Cancer 2017, 17, 20-37.

(3) Castanotto, D.; Rossi, J. J. The Promises and Pitfalls of RNA-Interference-Based Therapeutics. Nature 2009, 457, 426-433.

(4) Liu, Y. L.; Gunda, V.; Zhu, X.; Xu, X. D.; Wu, J.; Askhatova, D.; Farokhzad, O. C.; Parangi, S.;

Shi, J. J. Theranostic Near-infrared Fluorescent Nanoplatform for Imaging and Systemic SiRNA Delivery to Metastatic Anaplastic Thyroid Cancer. Proc. Natl. Acad. Sci. U. S. A. 2016, 113, $7750-7775$.

(5) Castleberry, S.; Wang, M.; Hammond, P. T. Nanolayered SiRNA Dressing for Sustained Localized Knockdown. ACS Nano 2013, 7, 5251-5261.

(6) Whitehead, K. A.; Langer, R.; Anderson, D. G. Knocking Down Barriers: Advances in SiRNA Delivery. Nat. Rev. Drug Discov. 2009, 8, 129-138.

(7) Khvorova, A.; Watts, J. K. The Chemical Evolution of Oligonucleotide Therapies of Clinical Utility. Nat. Biotechnol. 2017, 35, 238-248.

(8) Conde, J.; Oliva, N.; Atilano, M.; Song, H. S.; Artzi, N. Self-Assembled RNA-Triple-Helix Hydrogel Scaffold for MicroRNA Modulation in the Tumour Microenvironment. Nat. Mater. 2016, $15,353-363$.

(9) Won, Y. W.; Adhikary, P. P.; Lim, K. S.; Kim, H. J.; Kim, J. K.; Kim, Y. H. Oligopeptide Complex for Targeted Non-Viral Gene Delivery to Adipocytes. Nat. Mater. 2014, 13, 1157-1164.

(10) Jang, M.; Kim, J. H.; Nam, H. Y.; Kwon, I. C.; Ahn, H. J. Design of a Platform Technology 
for Systemic Delivery of SiRNA to Tumours Using Rolling Circle Transcription. Nat. Commun. 2015, $6,7930$.

(11) Pelaz, B.; Alexiou, C. H.; Alvarez-Puebla, R. A.; Alves, F.; Andrews, A. M.; Ashraf, S.; Balogh, L. P.; Ballerini, L.; Bestetti, A.; Brendel, C.; Bosi, S.; Carril, M.; Chan, W. C. W.; Chen, C. Y.; Chen, X. D.; Chen, X. Y.; Cheng, Z.; Cui, D. X.; Du, J. Z.; Dullin, C.; et al. Diverse Applications of Nanomedicine. ACS Nano 2017, 11, 2313-2381.

(12) Roh, Y. H.; Deng, J. Z.; Dreaden, E. C.; Park, J. H.; Yun, D. S.; Shopsowitz, K. E.; Hammond, P. T. A Multi-RNAi Microsponge Platform For Simultaneocs Controlled Delivery Of Multiple Small Interfering RNAs. Angew. Chem. Int. Ed. 2016, 55, 3347-3351.

(13) Wang, Y.; Kohane, D. S. External Triggering and Triggered Targeting Strategies for Drug Delivery. Nat. Rev. Mater. 2017, 2, 17020.

(14) Karimi, M.; Ghasemi, A.; Sahandi Zangabad, P.; Rahighi, R.; Moosavi Basri, S. M.; Mirshekari, H.; Amiri, M.; Shafaei Pishabad, Z.; Aslani, A.; Bozorgomid, M.; Ghosh, D.; Beyzavi, A.; Vaseghi, A.; Aref, A. R.; Haghani, L.; Bahrami, S.; Hamblin, M. R. Smart Micro/Nanoparticles in Stimulus-Responsive Drug/Gene Delivery Systems. Chem. Soc. Rev. 2016, 45, 1457-1501.

(15) Groves, B.; Chen, Y. J.; Zurla, C.; Pochekailov, S.; Kirschman, J. L.; Santangelo, P. J.; Seelig, G. Computing in Mammalian Cells with Nucleic Acid Strand Exchange. Nat. Nanotechnol. 2016, 11, 287-294.

(16) Afonin, K. A.; Viard, M.; Martins, A. N.; Lockett, S. J.; Maciag, A. E.; Freed, E. O.; Heldman, E.; Jaeger, L.; Blumenthal, R.; Shapiro, B. A. Activation of Different Split Functionalities on Re-Association of RNA-DNA Hybrids. Nat. Nanotechnol. 2013, 8, 296-304.

(17) Li, J.; Green, A. A.; Yan, H.; Fan, C. Engineering Nucleic Acid Structures for Programmable Molecular Circuitry and Intracellular Biocomputation. Nat. Chem. 2017, 9, 1056-1067.

(18) Bar-Ziv, R. Materials Science. DNA Circuits Get up to Speed. Science 2007, 318, 1078-1079. 
(19) Stoeger, T.; Battich, N.; Pelkmans, L. Passive Noise Filtering by Cellular Compartmentalization. Cell 2016, 164, 1151-1161.

(20) Thubagere, A. J.; Li, W.; Johnson, R. F.; Chen, Z.; Doroudi, S.; Lee, Y. L.; Izatt, G.; Wittman, S.; Srinivas, N.; Woods, D.; Winfree, E.; Qian, L. A Cargo-Sorting DNA Robot. Science 2017, 357, eaan6558.

(21) Adamala, K. P.; Martin-Alarcon, D. A.; Guthrie-Honea, K. R.; Boyden, E. S. Engineering Genetic Circuit Interactions within and between Synthetic Minimal Cells. Nat. Chem. 2017, 9, $431-439$.

(22) Surana, S.; Bhat, J. M.; Koushika, S. P.; Krishnan, Y. An Autonomous DNA Nanomachine Maps Spatiotemporal pH Changes in a Multicellular Living Organism. Nat. Commun. 2011, 2, 340.

(23) Clayden, J. Supramolecular Chemistry: Host in Translation. Nat. Nanotechnol. 2017, 12, 403-404.

(24) Linko, V.; Eerikainen, M.; Kostiainen, M. A. A Modular DNA Origami-Based Enzyme Cascade Nanoreactor. Chem. Commun. 2015, 51, 5351-5354.

(25) Zhao, Z.; Fu, J.; Dhakal, S.; Johnson-Buck, A.; Liu, M.; Zhang, T.; Woodbury, N. W.; Liu, Y.; Walter, N. G.; Yan, H. Nanocaged Enzymes with Enhanced Catalytic Activity and Increased Stability against Protease Digestion. Nat. Commun. 2016, 7, 10619.

(26) Fu, J.; Yang, Y. R.; Johnson-Buck, A.; Liu, M.; Liu, Y.; Walter, N. G.; Woodbury, N. W.; Yan, H. Multi-Enzyme Complexes on DNA Scaffolds Capable of Substrate Channelling with an Artificial Swinging Arm. Nat. Nanotechnol. 2014, 9, 531-536.

(27) Niu, J.; Hili, R.; Liu, D. R. Enzyme-Free Translation of DNA into Sequence-Defined Synthetic Polymers Structurally Unrelated to Nucleic Acids. Nat. Chem. 2013, 5, 282-292. 
(28) Meng, W.; Muscat, R. A.; McKee, M. L.; Milnes, P. J.; El-Sagheer, A. H.; Bath, J.; Davis, B. G.; Brown, T.; O'Reilly, R. K.; Turberfield, A. J. An Autonomous Molecular Assembler for Programmable Chemical Synthesis. Nat. Chem. 2016, 8, 542-548.

(29) He, Y.; Liu, D. R. Autonomous Multistep Organic Synthesis in a Single Isothermal Solution Mediated by a DNA Walker. Nat. Nanotechnol. 2010, 5, 778-782.

(30) McKee, M. L.; Milnes, P. J.; Bath, J.; Stulz, E.; O'Reilly, R. K.; Turberfield, A. J. Programmable One-Pot Multistep Organic Synthesis Using DNA Junctions. J. Am. Chem. Soc. 2012, $134,1446-1449$.

(31) Wheeldon, I.; Minteer, S. D.; Banta, S.; Barton, S. C.; Atanassov, P.; Sigman, M. Substrate Channelling as an Approach to Cascade Reactions. Nat. Chem. 2016, 8, 299-309.

(32) Küchler, A.; Yoshimoto, M.; Luginbühl, S.; Mavelli, F.; Walde, P. Enzymatic Reactions in Confined Environments. Nat. Nanotechnol. 2016, 11, 409-420.

(33) Chatterjee, G.; Dalchau, N.; Muscat, R. A.; Phillips, A.; Seelig, G. A Spatially Localized Architecture for Fast and Modular DNA Computing. Nat. Nanotechnol. 2017, 12, 920-927.

(34) Liang, C.-P.; Ma, P.-Q.; Liu, H.; Guo, X.; Yin, B.-C.; Ye, B.-C. Rational Engineering of a Dynamic, Entropy-Driven DNA Nanomachine for Intracellular MicroRNA Imaging. Angew. Chem. Int. Ed. 2017, 56, 9077-9081.

(37) Volker, J.; Klump, H. H.; Breslauer, K. J. DNA Energy Landscapes Via Calorimetric Detection of Microstate Ensembles of Metastable Macrostates and Triplet Repeat Diseases. Proc. Natl. Acad. Sci. U. S. A. 2008, 105, 18326-18330.

(38) Seelig, G.; Yurke, B.; Winfree, E. Catalyzed Relaxation of a Metastable DNA Fuel. J. Am. Chem. Soc. 2006, 128, 12211-12220.

(39) Xing, Y.; Yang, Z.; Liu, D. A Responsive Hidden Toehold to Enable Controllable DNA Strand Displacement Reactions. Angew. Chem. Int. Ed. 2011, 50, 11934-11936. 
(40) Sun, W.; Ji, W.; Hall, J. M.; Hu, Q.; Wang, C.; Beisel, C. L.; Gu, Z. Self-Assembled DNA Nanoclews for the Efficient Delivery of CRISPR-Cas9 for Genome Editing. Angew. Chem. Int. Ed. 2015, 54, 12029-12033.

(41) Deng, R.; Tang, L.; Tian, Q.; Wang, Y.; Lin, L.; Li, J. Toehold-Initiated Rolling Circle Amplification for Visualizing Individual MicroRNAs in Situ in Single Cells. Angew. Chem. Int. Ed. 2014, 53, 2389-2393.

(42) Lv, Y.; Hu, R.; Zhu, G.; Zhang, X.; Mei, L.; Liu, Q.; Qiu, L.; Wu, C.; Tan, W. Preparation and Biomedical Applications of Programmable and Multifunctional DNA Nanoflowers. Nat. Protoc. 2015, 10, 1508-1524.

(43) Lau, K. L.; Hamblin, G. D.; Sleiman, H. F. Gold Nanoparticle 3D-DNA Building Blocks: High Purity Preparation and Use for Modular Access to Nanoparticle Assemblies. Small 2014, 10, 660-666.

(44) Mok, H.; Lee, S. H.; Park, J. W.; Park, T. G. Multimeric Small Interfering Ribonucleic Acid for Highly Efficient Sequence-Specific Gene Silencing. Nat. Mater. 2010, 9, 272-278.

(45) Lee, S. J.; Huh, M. S.; Lee, S. Y.; Min, S.; Lee, S.; Koo, H.; Chu, J. U.; Lee, K. E.; Jeon, H.; Choi, Y.; Choi, K.; Byun, Y.; Jeong, S. Y.; Park, K.; Kim, K.; Kwon, I. C. Tumor-Homing Poly-SiRNA/Glycol Chitosan Self-Cross-Linked Nanoparticles for Systemic SiRNA Delivery in Cancer Treatment. Angew. Chem. Int. Ed. 2012, 51, 7203-7207.

(46) Wu, P.; Hwang, K.; Lan, T.; Lu, Y. A DNAzyme-Gold Nanoparticle Probe for Uranyl Ion in Living Cells. J. Am. Chem. Soc. 2013, 135, 5254-5257.

(47) Yang, Y.; Huang, J.; Yang, X.; Quan, K.; Wang, H.; Ying, L.; Xie, N.; Ou, M.; Wang, K. FRET Nanoflares for Intracellular mRNA Detection: Avoiding False Positive Signals and Minimizing Effects of System Fluctuations. J. Am. Chem. Soc. 2015, 137, 8340-8343.

(48) Ohta, S.; Glancy, D.; Chan, W. C. W. DNA-Controlled Dynamic Colloidal Nanoparticle 
Systems For Mediating Cellular Interaction. Science 2016, 351, 841-845.

(49) Chen, G.; Liu, D.; He, C.; Gannett, T. R.; Lin, W.; Weizmann, Y. Enzymatic Synthesis of

Periodic DNA Nanoribbons for Intracellular $\mathrm{pH}$ Sensing and Gene Silencing. J. Am. Chem. Soc. 2015, 137, 3844-3851.

(50) Liang, L.; Li, J.; Li, Q.; Huang, Q.; Shi, J.; Yan, H.; Fan, C. Single-Particle Tracking and Modulation of Cell Entry Pathways of a Tetrahedral DNA Nanostructure in Live Cells. Angew. Chem. Int. Ed. 2014, 53, 7745-7750.

(51) Han, D.; Wu, C.; You, M.; Zhang, T.; Wan, S.; Chen, T.; Qiu, L.; Zheng, Z.; Liang, H.; Tan, W. A Cascade Reaction Network Mimicking the Basic Functional Steps of Adaptive Immune Response. Nat. Chem. 2015, 7, 835-841. 


\section{FIGURE CAPTIONS:}

Figure 1. Schematic illustration of intracellular siRNA cascade assembly with a microRNA-triggered DNM in living cells. (a) Synthesis of DNM and DNM/FPEI, and (b) target cell-specific delivery of DNM/FPEI for miR-21 triggered assembly of siRNA in living cells.

Figure 2. Characterization of DNM and DNM/FPEI nanocomposites. (a) PAGE analysis of DNA primer, DNA cycle, DNA scaffold, DR, D'R', DNM and DNA ladder marker (lanes 1-7). (b) AFM phase image of DNM. Scale bar: $200 \mathrm{~nm}$. (c) Hydrodynamic diameter distribution of DNM/FPEI. (d) AFM phase image of DNM/FPEI. Scale bar: $800 \mathrm{~nm}$.

Figure 3. Characterization of siRNA generation with miRNA-triggered DNM. (a) PAGE image of (1) $5 \mu \mathrm{M} R \mathrm{RR}^{\prime}$, (2) $2 \mu \mathrm{M}$ DNM, (3) mixture of $2 \mu \mathrm{M}$ DNM and $10 \mathrm{nM}$ miR-21, (4) mixture of $2 \mu \mathrm{M}$ DNM and $10 \mathrm{nM}$ control miRNA, and (5) $2 \mu \mathrm{M}$ DNA ladder marker. (b) Fluorescence spectra of SQ-DNM (DNM) and SQ-DNM in response to $10 \mathrm{nM}$ miR-21 (DNM+miR-21) and $10 \mathrm{nM}$ miR-145 (DNM+miR-145) at $\lambda_{\mathrm{ex}}$ of $510 \mathrm{~nm}$, and SQ-NR-DNM in response to $10 \mathrm{nM} \mathrm{miR}-21$ (NR-DNM+miR-21). (c) Fluorescence spectra of bicolor DNM prepared with FAM-R and TAMRA-R' at $\lambda_{\mathrm{ex}}$ of $480 \mathrm{~nm}$ in response to $5 \mathrm{nM}$ and $10 \mathrm{nM}$ miR-21. Fluorescence spectra of (d) SQ-DNM and (e) the mixture of SQ-DR and D'R' after incubated with miR-21 at various concentrations for $60 \mathrm{~min}$.

Figure 4. Characterization of siRNA cascade generation with miRNA-triggered DNM in HeLa cells. Confocal fluorescence images of HeLa cells incubated with SQ-DNM/FPEI, SQ-NR-DNM/FPEI, and antisense miR-21 treated HeLa cells (control HeLa) incubated with SQ-DNM/FPEI as control. Scale bar: $20 \mu \mathrm{m}$.

Figure 5. Intracellular therapeutic effect of miRNA-triggered DNM. (a) Real-time PCR characterization of VEGF mRNA expression and (b) ELISA characterization of protein expression in 
HeLa cells, and (c) apoptosis of HeLa cells after incubated with 100 nM FPEI, FR-DNM/FPEI, NC-DNM/FPEI, NR-DNM/FPEI and DNM/FPEI for $3 \mathrm{~h}$ and then incubated in DMEM for $48 \mathrm{~h}$ at $37{ }^{\circ} \mathrm{C}$, and HeLa cells without any treatment as control. The data error bars indicate means \pm SD $(n=$ 3). $* * P<0.01$ (two-tailed Student's t-test). The cell apoptosis is tested with Annexin V-FITC/PI apoptotic kit.

Figure 6. In vivo demonstration of therapeutic applicability of miRNA-triggered DNM. (a) Tumour volumes of mice groups with intravenous injection of different nanocomposites every two days. Error bars indicate means $\pm \mathrm{SD}(n=5) . * * P<0.01$ (two-tailed Student's t-test). (b) Representative images of HeLa tumours collected from 1) DNM/FPEI, 2) NR-DNM/FPEI, 3 ) NC-DNM/FPEI and 4) PBS injected mice groups at day 14. Scale bar: $1 \mathrm{~cm}$. 


\section{Figure 1}

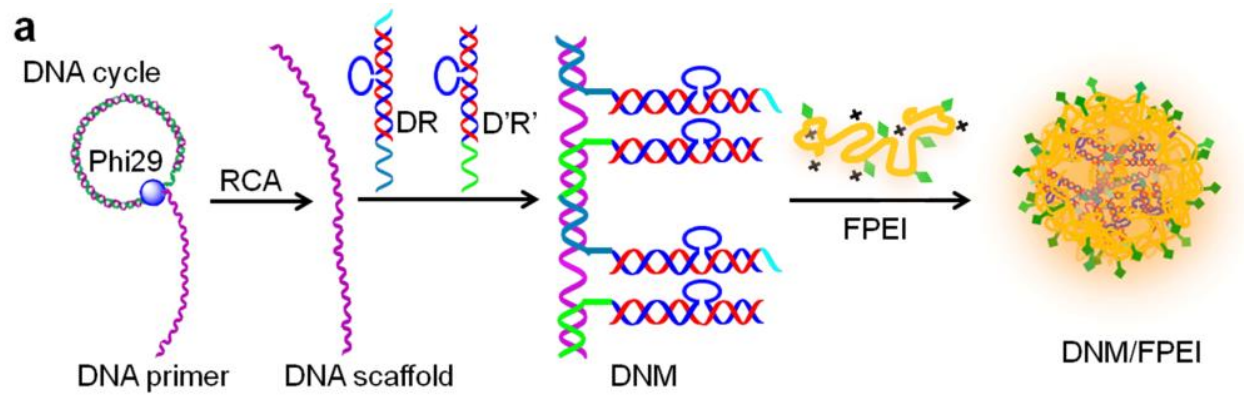

b

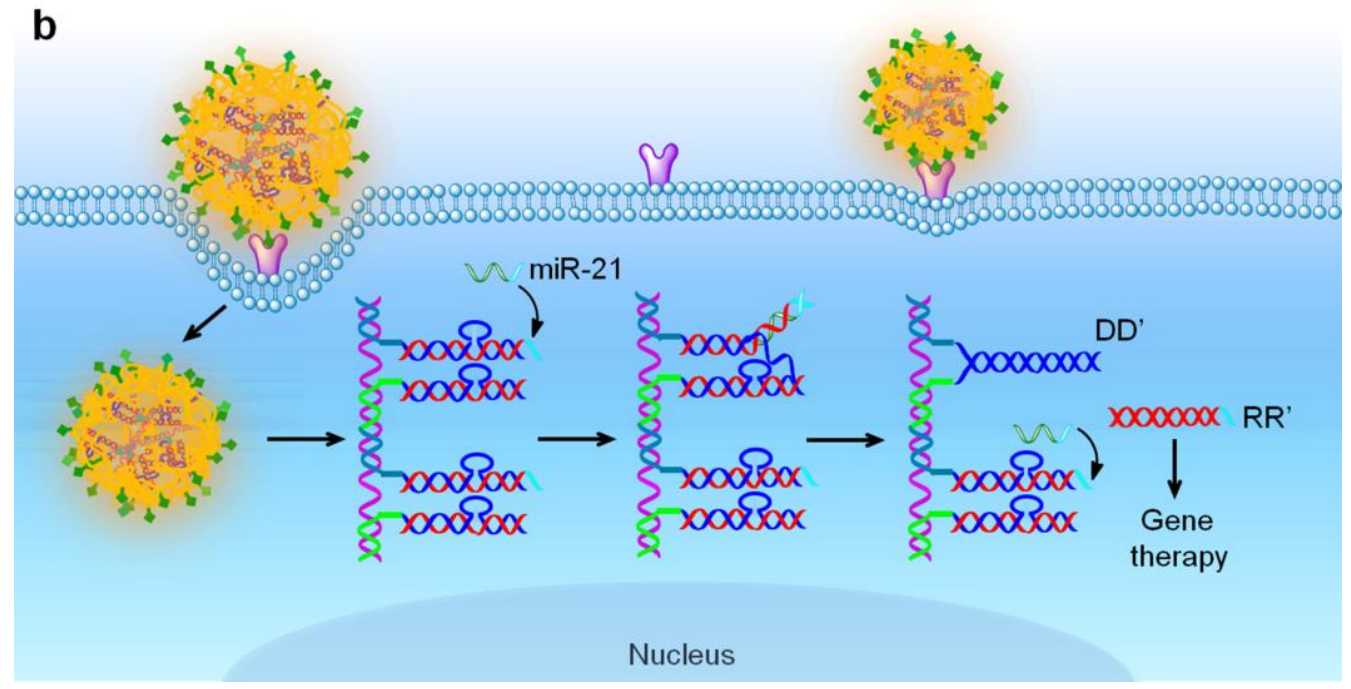


Figure 2

a
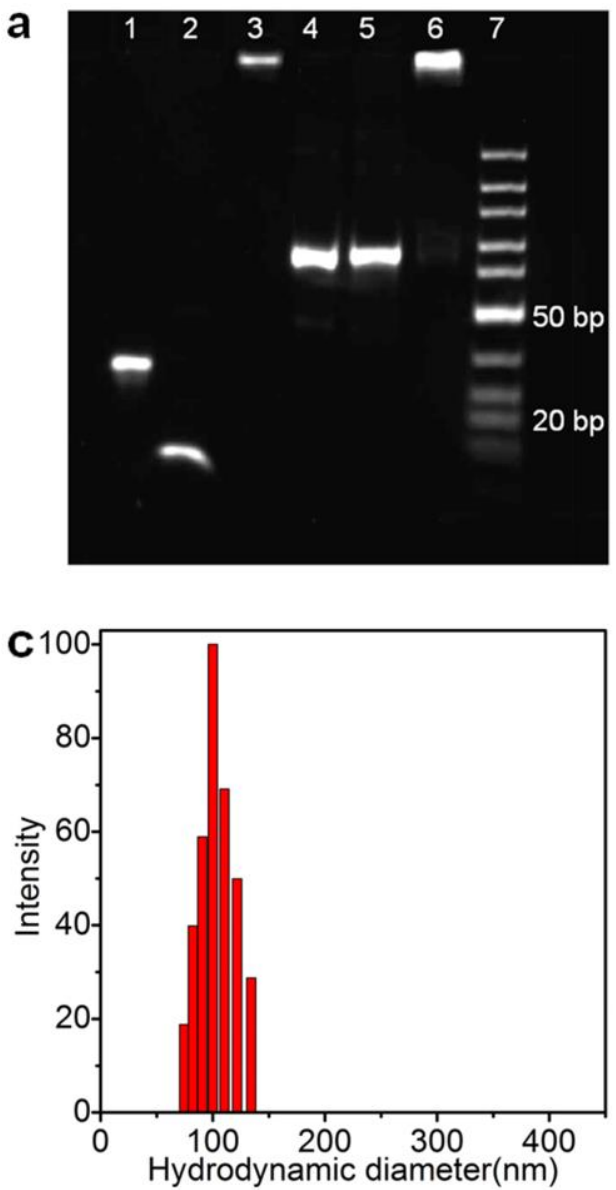

b
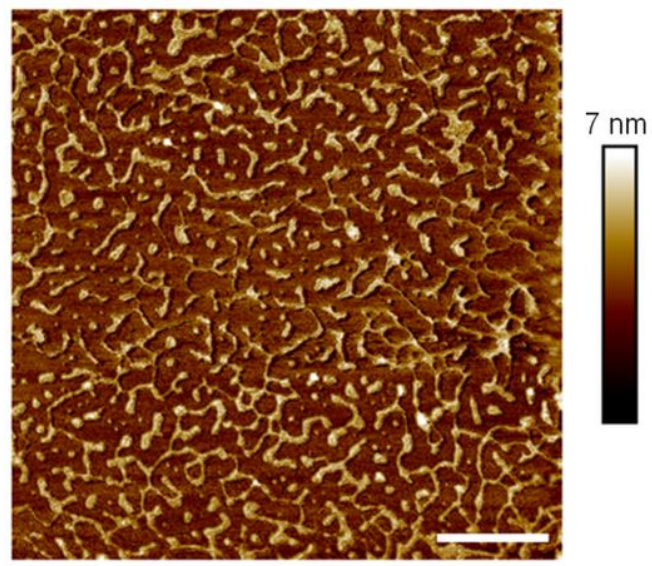

d

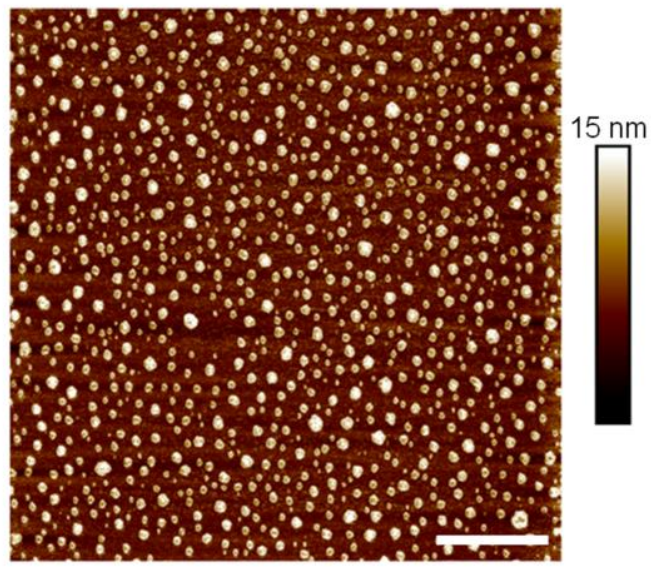


Figure 3
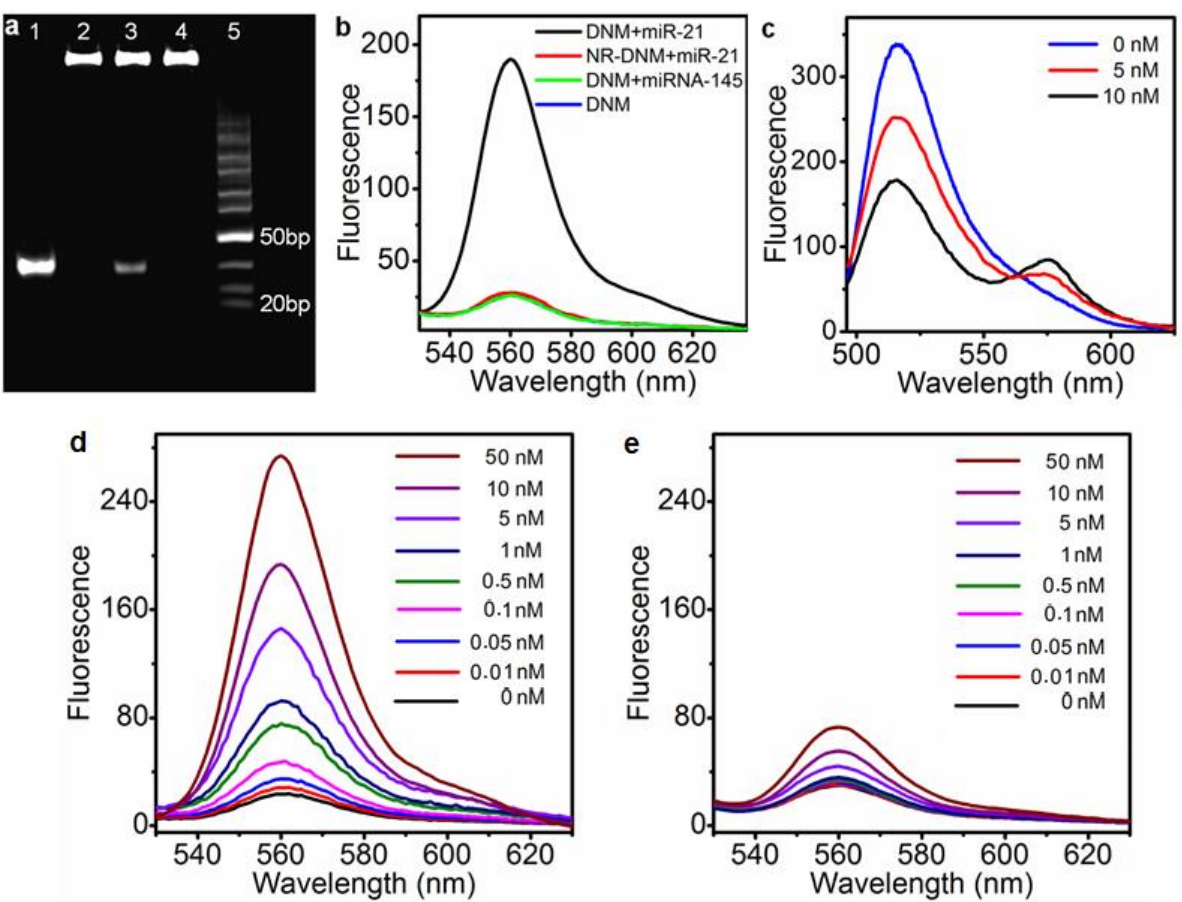
Figure 4

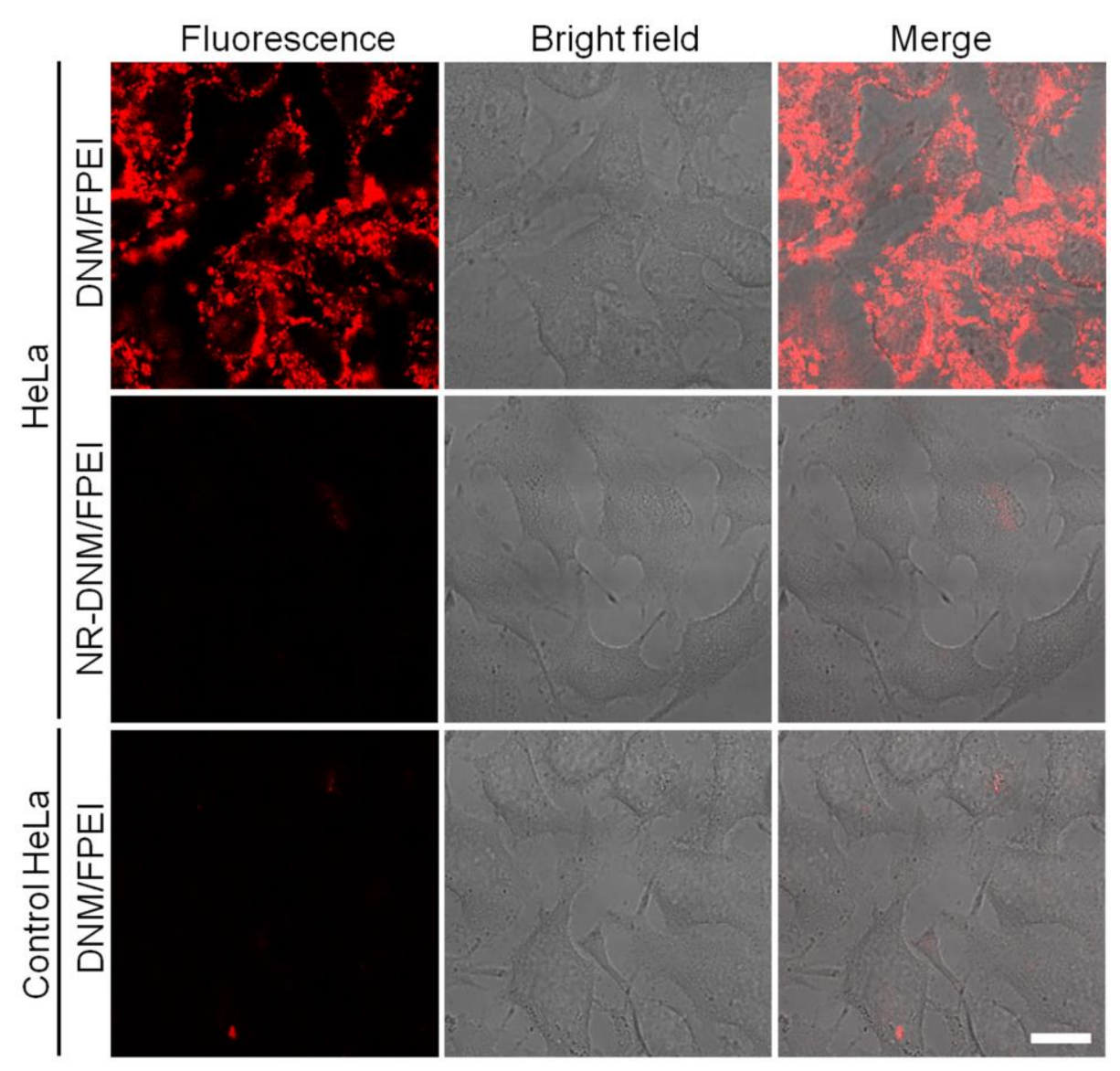




\section{Figure 5}
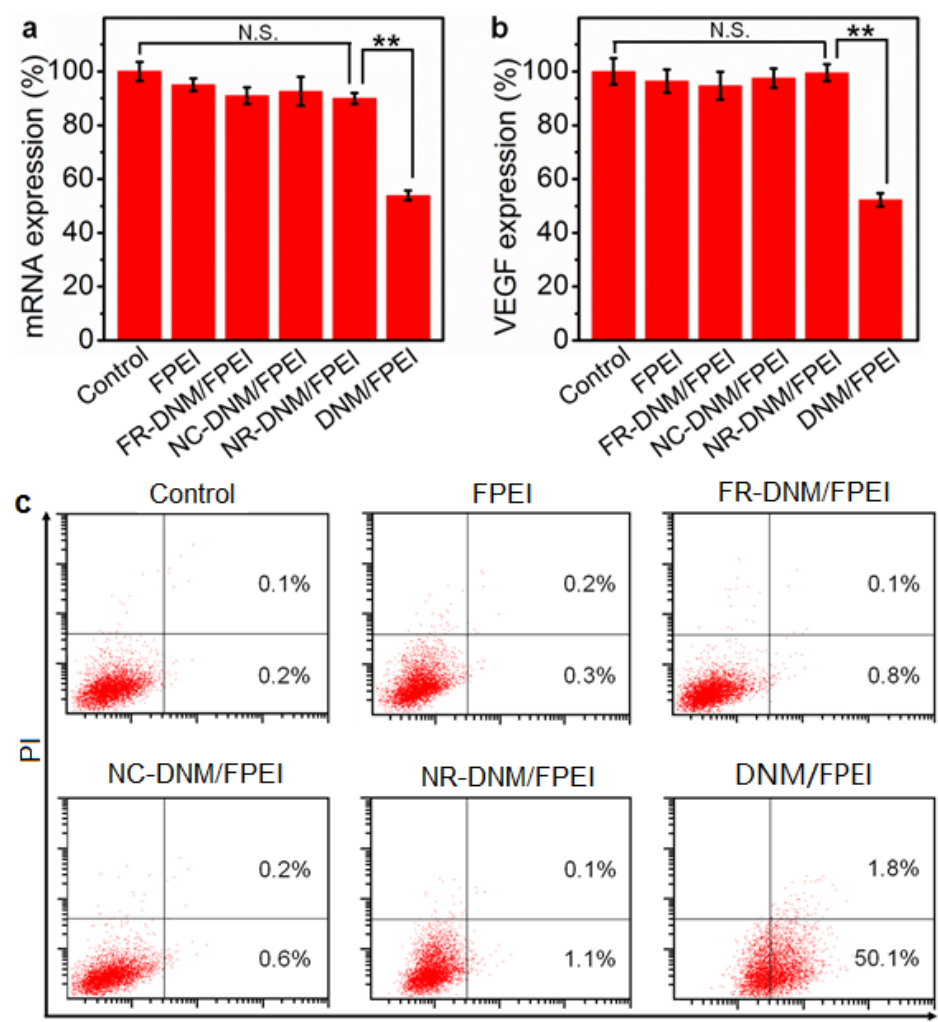

Annexin V-FITC 
Figure 6
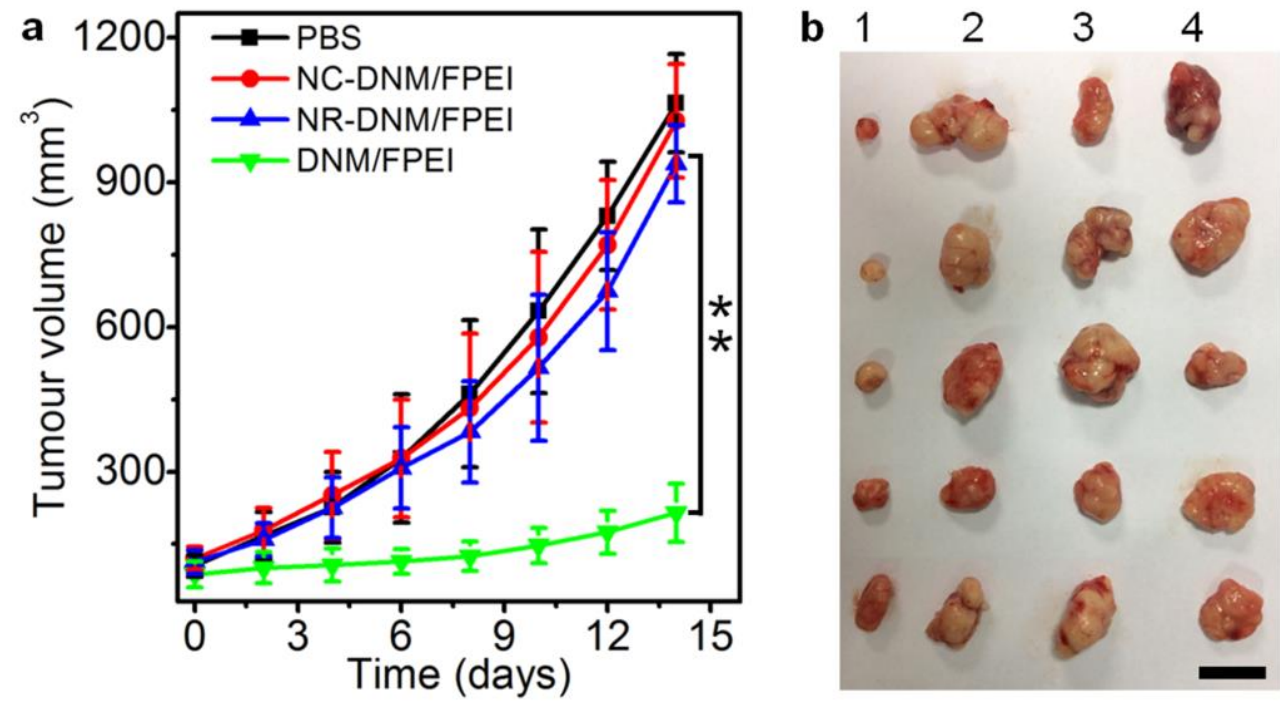
For TOC only

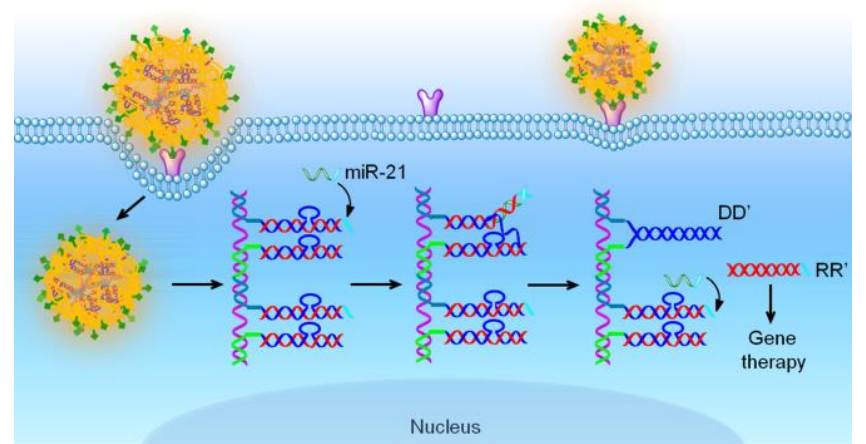

